\title{
Offener Brief
}

\author{
an \\ Seine Hoheit den Erbprinzen Bernhard \\ von Sachsen-Meiningen.
}

\section{Hoheit!}

Es sei mir gestattet Eurer Hoheit meiner tiefen Dankbarkeit für all das Gute, was Hochdieselben mir erwiesen, hier an dieser Stelle öffentlich Ausdruck zu geben, und zugleich zu erklären, dass, wenn dieses Buch sich den Deutschen als nützlich erweist, ich es zum grossen Theil Eurer Hoheit verdanke.

Ich habe die Ehre gehabt, Eure Hoheit im Neugriechischen zu unterrichten; Hochdieselben beherrschen gegenwärtig meine Muttersprache, wie ein geborener Grieche, so dass Sie in Ihren Mussestunden eine Übersetzung von Schiller's "Fiesko" und Lessing's "Emilia Galotti" verfasst haben, welche von den Griechen als vorzüglich gelungen begrüsst worden ist. Aber Eure Hoheit werden sich wohl noch erinnern, wie sehr der Mangel an geeigneten Lehrbüchern das Erlernen der neugriechischen Sprache erschwert. Durch die mehrjährige Erfahrung, welche ich gewann, indem ich Eure Hoheit unterrichtete, wurde es mir klar, auf welche Art und Weise ein Buch verfasst werden müsse, um den Deutschen, welche diese Sprache erlernen wollen, von Nutzen zu sein. 
VIII

Freilich sind zwei von Griechen verfasste Grammatiken vorhanden, die eine von Angelos Vlachos, die andere von Antonios Jannarakis, aber sie entsprechen den Bedürfnissen der Deutschen nur unvollkommen, denn die erstere, zu elementar, ist ausschliesslich für die Kreise bestimmt, welche der alten Sprache bereits mächtig sind, die zweite, zwar genauer und ausführlicher, ist viel zu theoretisch gehalten; beide aber haben den grossen Fehler gemein, dass sie nur in der Schriftsprache Übungen enthalten.

Eure Hoheit wissen, dass im Neugriechischen der Unterschied zwischen Schrift- und Umgangssprache so gross ist, wie in keiner anderen europäischen Sprache, und es ist eine Thatsache, dass dieselben Griechen, die in Journalen und Büchern, im Parlamente und den Tribunalen sich der gewähltesten Worte und einer reinen grammatischen Ausdrucksweise bedienen, in Athen ebenso wie in Konstantinopel und Smyrna bei der Unterhaltung nur die Volkssprache anwenden, eine Sprache, die einerseits zahlreiche in der Schriftsprache nicht vorkommende Wörter enthält, andrerseits viele abgekürzte oder verảnderte grammatische Formen hat, und überall, sowohl im Palaste des Königs wie auch in dem geringsten Krämerladen als Umgangssprache gebraucht wird. Vielleicht erinnern sich Eure Hoheit noch jenes Augenblickes bei Gelegenheit Ihrer ersten Begegnung mit dem Prinzen Georg von Griechenland in London, wo derselbe sich mit den Worten der Volkssprache:

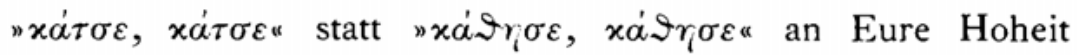
wandte, und Hochdieselben ihn in Folge dessen nicht sogleich verstanden.

Es war also nothwendig, dass ein Buch erschiene, welches die Deutschen in praktischer Weise neugriechische Schrift- und Umgangssprache zugleich lehrt. Der Deutsche will ja nicht allein die Sprache der Zeitungen und Bücher verstehen lernen, sondern 
IX

vor allem sich mit dem Griechen selbst mündlich verständigen können.

Bei der Abfassung dieser Grammatik bin ich demnach einer Methode gefolgt, welche ich auch beim Unterrichte im Seminar für orientalische Sprachen an der Königlichen FriedrichWilhelms-Universität zu Berlin anwende. Die Übungen sind gleichzeitig in der Schrift- und Umgangssprache gegeben, so dass dem Deutschen der Unterschied zwischen beiden klar vor Augen geführt wird. Ausser den Übungen habe ich auch kleine Gespräche eingefügt, welche natürlich nur die Umgangssprache enthalten. Ich habe soviel wie möglich die Theorie zu vereinfachen gesucht; denn mein Bestreben war, ein praktisches Buch zu schreiben.

Die Gründung des orientalischen Seminars hat in jüngster Zeit in Deutschland neue Anregung zum Studium orientalischer Sprachen gegeben. Dabei durfte das Neugriechische nicht vernachlässigt werden, da diese Sprache nicht nur im Königreich Griechenland selbst, sondern auch weit über dessen Grenzen hinaus in den Häfen der Türkei und Kleinasiens vorherrscht.

Ich hoffe, dass diejenigen, welche sich dem Studium dieser für die Levante hochwichtigen Sprache widmen, durch mein Buch Erleichterung und Anregung finden werden.

Berlin, im Januar I89ı.

In tiefster Ehrfurcht

Eurer Hoheit dankbar ergebener

J. K. Mitsotakis. 